\title{
Auditory Neuropathy Spectrum Disorder
}

National Cancer Institute

\section{Source}

National Cancer Institute. Auditory Neuropathy Spectrum Disorder. NCI Thesaurus. Code C116364.

A hearing disorder characterized by impaired transmission of signals through the auditory nerve, resulting in mild to severe hearing loss and poor speech perception. 